\title{
EL FINAL DE LA VIDA COMO DESAFÍO A LA ÉTICA SANITARIA
}

\author{
David E. Pérez González* \\ Universidad de La Laguna
}

\section{RESUMEN}

La Constitución española de 1978 reconoce en su artículo 10 la dignidad de la persona, los derechos inviolables que le son inherentes, el libre desarrollo de la personalidad, el respeto a la ley y a los derechos de los demás como fundamento del orden político y de la paz social. Las normas relativas a los derechos fundamentales y a las libertades que la Constitución reconoce se interpretarán de conformidad con la Declaración Universal de Derechos Humanos y los tratados y acuerdos internacionales sobre las mismas materias ratificados por España. De ahí que este valor, dignidad, sirva de base en su análisis para encuadrar lo que se conoce como muerte digna. Sobre esta premisa principalmente se plantean varias dudas con respecto a la combinación de varios de los preceptos de la Carta Magna que en su aplicación al ámbito de la salud pueden generar discrepancia. Me refiero, por un lado, al artículo 15, que pugna por la proclamación tanto del derecho a la vida como del derecho a no recibir tratos inhumanos y degradantes. Y por otro lado vemos que ese mismo artículo 15 se enfrenta a los preceptos que la Constitución dedica al derecho a la libertad personal en sus diversas variantes.

Palabras Clave: final de vida, ética sanitaria, derecho a morir.

THE END OF LIFE AS A CHALLENGE TO HEALTH ETHICS

\section{Abstract}

Article 10 of the Spanish Constitution of 1978 recognizes the dignity of the individual, the inviolable rights inherent in it, the free development of personality, respect for the law and the rights of others as the basis of political order and social peace. The rules relating to fundamental rights and freedoms recognized by the Constitution shall be interpreted in accordance with the Universal Declaration of Human Rights and the international treaties and agreements on the same subjects ratified by Spain. Hence, this value of dignity serves as a basis in its analysis for framing a dignified death. On this premise, several doubts are raised regarding the combination of several of the precepts of the Magna Carta, which, in their application to the field of health, can generate discrepancies. We refer, on the one hand, to Article 15, which calls for the proclamation of both the right to life and the right not to be subjected to inhuman and degrading treatment. And on the other hand, we see that this same article 15 confronts the precepts that the Constitution dedicates to the right to personal freedom in its various variants.

Keywords: end of life, health ethics, right to die.

DOI: https://doi.org/10.25145/j.cuidar.2020.00.04

Revista CuIDAR, 0; junio 2020, pp. 49-59; ISSN: 2660-4426 


\section{DERECHO A VIVIR VERSUS DERECHO A MORIR}

Profundizamos observando que si por un lado se reconoce el derecho a la vida, por el otro lado, tenemos tanto la prohibición de practicar tratos inhumanos y degradantes como la posibilidad para ejercitar (por ejemplo artículo 10) el libre desarrollo de la personalidad mediante el pleno ejercicio del individuo de la libertad de decisión sobre cuestiones que le incumben, nos encontramos con un verdadero problema de confrontación de derechos ${ }^{1}$. Desde luego, y por eso no voy a entrar en ello, ninguna discusión se plantea sobre el carácter relativo de los derechos, otra cosa es cómo se produce su convivencia pacífica ${ }^{2}$. En su naturaleza el derecho a la vida plasmado en ese artículo 15 refleja un valor supremo del ordenamiento jurídico que merece cualquier tipo de protección, lo que impide, solamente así sesgadamente analizado, que no se pueda reconocer la libre voluntad de querer vivir o de querer morir, siendo, en consecuencia, este último indisponible por su titular. El reconocimiento y protección del derecho a la vida no tiene como correlato el mismo derecho a morir con idéntica protección ${ }^{3}$. Sin embargo, al introducir el elemento de la libertad, que permite a su titular tomar las decisiones que a su propia vida le conciernen, se abre la vía para que en la gestión de su propia vida en el ejercicio del derecho a la libertad se le permita disponer de ella ${ }^{4}$. Esta línea de pensamiento nutre las tesis que defienden actuaciones proeutanásicas con base en la defensa del valor supremo del ser humano como es la dignidad, invocando que «lo que aquí se propone es centrar el reconocimiento de la eutanasia sobre la noción de la protección de un ejercicio voluntario y consciente del derecho a la vida que se disfruta en vida

* Profesor de la Universidad de La Laguna. Tenerife. España, e-mail: dpergon@ull.es.

${ }^{1}$ En este sentido se defiende la postura por la que el patrimonio común de la humanidad debe estar no sólo reconocido, sino perfectamente protegido, tal y como lo hacen sus defensores al «destacar la responsabilidad de la humanidad ante el genoma humano, en tanto que elemento constitutivo de la identidad de cada uno, así como la identidad misma de toda la humanidad», BLÁzQuez Ruiz, Javier, Derechos Humanos y Proyecto Genoma, Biblioteca de Derecho y ciencia de la vida, Comares, Granada, 1999, p. 2.

2 En este sentido, véase Rodríguez Calero, Juan M., Creación judicial y derechos fundamentales, Universidad Libre, Bogotá, 2012, p. 251 y ss.

${ }^{3}$ Una posición en contra radical identificando la disposición de la vida como un correlato lógico del derecho a la vida, en Ara Pinilla, Ignacio, «Los frentes abiertos del testamento vital», en López Hernández, José, Navarro Aznar, Fernando y Ramón Torres, José (eds.), Estudios de Filosofía del Derecho y Filosofía Politica. Homenaje al Profesor Alberto Montoro Ballesteros, Universidad de Murcia, 2013, p. 317, para quien «no tendría sentido hablar del derecho a la muerte porque con ello no se estaría reivindicando otra cosa diferente a la posibilidad de no ejercitar, o en su caso, ejercitar negativamente la prerrogativa inherente al derecho a la vida». La postura contraria representa uno de los casos de manipulación del sentido de los derechos que denuncia el propio Ara Pinilla, Ignacio, «La autocomplacencia estética de la cultura jurídica», en SÁnchez Bravo, Álvaro (dir.), Democracia, pluralismo y derechos humanos, Cívitas, Pamplona, 2019, pp. 285-305.

${ }^{4}$ Extremando esta libertad hasta llegar a «el pilar básico del concepto de eutanasia, en la reivindicación social como derecho humano, es la libre voluntad del enfermo", Ruiz Vadillo, Enrique, "El derecho a la vida y a la integridad física», en XII Jornadas de Estudio. Los Derechos Fundamentales y Libertades Públicas, vol. 1, Secretaria General Técnica, Centro de Publicaciones, Madrid, 1992, p. 37. 
eludiendo cualquier consideración trasmundana, y que recomienda materializar ese derecho a la vida a través del derecho a llevar una vida digna ${ }^{5}$. Es decir, no existe derecho a morir, tampoco el deber de vivir, de lo que podríamos hablar es de una posible libertad personal para vivir o morir. De ahí que el hecho de que se pueda debatir sobre la decisión de quien asume el riesgo de morir en un acto de voluntad que sólo a él afecta sea respetable y en consecuencia lícito, ya que «la vida es comúnmente entendida como un valor relevante. Pero también lo es, desde luego, la libertad. El problema surge cuando en uso del valor que representa la libertad se pretende destruir el valor de la vida $»^{6}$. En esta línea lo hace la Ley 41/2002, de 14 de noviembre, básica reguladora de la autonomía del paciente y de derechos y obligaciones en materia de información y documentación clínica que permite al paciente rechazar un tratamiento. Pretensión ésta avalada en los principios básicos inspiradores de la ley, como es la dignidad, que de conformidad con su artículo 2 apartado 1 propugna que la dignidad de la persona humana, el respeto a la autonomía de su voluntad y a su intimidad orientarán toda la actividad encaminada a obtener, utilizar, archivar, custodiar y transmitir la información y la documentación clínica. También la Ley canaria 1/2015, de 9 de febrero, de derechos y garantías de la dignidad de la persona ante el proceso final de su vida en su artículo 18.1 regula los deberes en la toma de decisiones clínicas obligando al médico, antes de proponer cualquier intervención sanitaria a una persona en el proceso final de su vida, y siempre que ésa sea su propuesta en el proceso de salud de su paciente, a someter la misma al consentimiento libre y voluntario de la persona, que podrá en su caso aceptar la intervención propuesta, elegir libremente entre las opciones clínicas disponibles, o rechazarla.

Esta postura ha inclinado a nuestro sistema jurídico a la correspondiente habilitación legal, claro está, con las oportunas reservas, puesto que en ningún caso mediante esta libertad de decisión se pueden amparar prácticas eutanásicas ${ }^{7}$, al exi-

${ }^{5}$ En realidad, «esta propuesta de concebir el derecho a la vida a través del derecho a la dignidad, a su vez, participa de buen encaje en nuestro sistema jurídico constitucional», Suarez LlaNos, Leonor, «La ley de la muerte. Eutanasia, ética y derechos», en Anuario de Filosofía del Derecho, tomo XXVIII, 2012, pp. 341-342.

${ }^{6}$ Miraut Martín, Laura, «El testamento vital como expresión de la autonomía individual», en Miraut Martín, Laura (editora), Imágenes contemporáneas de la realización de los derechos en la cultura jurídica iberoamericana, Dykinson, Madrid, 2018, p. 165.

7 Díez Ripollés define la eutanasia como aquel comportamiento que, de acuerdo con la voluntad o interés de otra persona que padece una lesión o enfermedad incurable, generalmente mortal, que le causa graves sufrimientos y/o afecta considerablemente a su calidad de vida, da lugar a la producción, anticipación, o no aplazamiento de la muerte del afectado, Díez Ripollés, José Luis y Muñoz SÁnchez, Juan, El tratamiento jurídico de la Eutanasia. Una perspectiva de Derecho comparado, Tirant lo Blanc, Valencia 1996, p. 511. En este mismo sentido la Asociación Médica Mundial califica la eutanasia como una práctica contra la ética y la define como «el acto de terminar deliberadamente la vida de un paciente, incluso ante la petición de éste», Álvarez del Río, Asunción, Práctica y ética de la eutanasia, Fondo de Cultura Económica, México, 2005, p. 31. 
gir el paciente a los profesionales de la salud actuaciones que directamente tengan como objetivo poner fin a su vida ${ }^{8}$.

Sobre esta base se pugna porque la dignidad humana debe ser entendida a lo largo de la vida sin posibles fisuras que desvirtúen su esencia, ya que «la sustantividad de la dignidad humana en el entramado axiológico de los sistemas jurídicos está fuera de discusión»". Desde el nacimiento hasta la muerte, incluida ésta, debe desarrollarse bajo los parámetros que ese valor marca. De ahí que aparezcan estos nuevos conceptos como el de calidad de vida o el de muerte digna ${ }^{10}$. Las legislaciones de los países de nuestro entorno se configuran con sustento en éste, entre otros valores, que en la actualidad inspiran una concepción más abierta que sobrepasa las fronteras de los hábitos conductuales que han orientado hasta ahora el final de la vida, porque "todos tenemos derecho a vivir y la obligación de dejar vivir a los demás, pero también el derecho a morir con dignidad $»^{11}$. Esto, en la práctica, obliga al legislador democrático a una revisión de los sistemas jurídicos actuales para adaptarlos a las nuevas conductas que la sociedad paulatinamente está aceptando y asumiendo como propias ${ }^{12}$. Los individuos proyectan su existencia en las leyes de la $v_{\text {vida }}{ }^{13}$, lo que no siempre y en todos los casos conlleva necesariamente el desarrollo corporal hasta la muerte natural, alejada de cualquier intervención humana (eso es, dotada de todos los sufrimientos que pueda originar). Hoy en día se defiende, y así lo han puesto de manifiesto algunos ordenamientos jurídicos, una capacidad para decidir en libertad como otra opción más, para que una vez que llegue el momento final podamos decidir morir dignamente ${ }^{14}$, llegando incluso a la cúspide del derecho

${ }^{8}$ Sobre este tema puede profundizarse en SANZ-OrTiz, Jaime, «Es posible gestionar el proceso de morir? Voluntades anticipadas», en Medicina Clínica, vol. 126, abril 2006, p. 620, habla de que en los últimos tiempos sobre todo a partir de la década de los 70 , hay un «crecimiento inusitado de los movimientos que intentan ayudar a morir».

9 Pérez González, David E., «Revisión de los valores implicados en el proceso de emancipación individual en la sociedad trasnacional», en Revista de Derecho UNED, n. ${ }^{\circ}$ 14, UNED, 2014, p. 444.

${ }^{10}$ Sobre voluntarismo véase la obra de Dworkin, Ronald, El dominio de la vida, Ariel, Madrid, 1994, p. 223 y ss.

11 Ruiz Vadillo, Enrique, «Comentario al art. 143 del nuevo Código penal», en Conde-Pumpido Ferreiro, Cándido (dir.), Código Penal. Doctrina y Jurisprudencia, tomo II, Trivium, Madrid, 1997, p. 1822; sobre este asunto se puede consultar también NúÑEz PAz, Miguel Ángel, Homicidio consentido, eutanasia y derecho a morir con dignidad, Tecnos, Madrid, 1999.

${ }_{12} \mathrm{Al}$ respecto el trabajo de Cortina, Adela, Etica aplicada y democracia radical, Tecnos, Madrid, 1993; y también Hotal, Augusto, Ética I, Universidad de Comillas, Madrid, 1994.

13 En definitiva, «la vida, que es el presupuesto material del ejercicio de cualesquiera otros derechos», sirve de sustento para el desarrollo de la individualidad de la ciudadanía. De ahí que la titularidad de derechos sea reconocida y hasta a veces impuesta al individuo, lo que consecuentemente implica que los derechos humanos sean atribuidos al individuo independientemente de su consentimiento, Díez Ripollés, José Luis, «Eutanasia y Derecho», en Anuario Filosofía del Derecho, tomo XII, 1995, p. 91.

${ }^{14}$ Véase Gracia, Diego (ed.), Morir con dignidad: Dilemas éticos en el final de la vida, Fundación de Ciencias de la Salud-Editorial Doce Calles, Madrid, 1996; también Juanatey Dorado, Carmen, Derecho, suicidio, eutanasia, Servicio de Publicaciones de la Secretaría del Ministerio de Jus- 
a decidir libremente como son los casos en los que se reconoce la eutanasia, como por ejemplo en Holanda, que despenaliza incluso la eutanasia activa, o Gran Bretaña, que, más reticente, sólo permite la eutanasia pasiva y la indirecta.

En España en diversas ocasiones se ha intentado una regulación más aperturista a la actual en relación con las prácticas eutanásicas pero todavía no se ha aprobado una ley en ese sentido, aunque en el mes de enero de 2020 se ha presentado ante la mesa del Congreso de los Diputados una proposición de Ley Orgánica de Regulación de la Eutanasia que pretende, tal y como revela su exposición de motivos, dar una respuesta jurídica, sistemática, equilibrada y garantista a una demanda sostenida de la sociedad actual.

Sobre esta base el propio preámbulo de la proposición de ley enfatiza que la legalización y la regulación de la eutanasia se asientan sobre la compatibilidad de unos principios esenciales que son basamento de los derechos de las personas, tal y como hemos indicado al referirnos a los que han sustentado la institución del consentimiento informado del paciente en nuestro país, y que son así recogidos en la Constitución española. Son, de un lado, los derechos fundamentales a la vida y a la integridad física y moral, y de otro, bienes constitucionalmente protegidos como son la dignidad, la libertad o la autonomía de la voluntad.

Los ordenamientos jurídicos que defienden potenciar la libertad de elección del individuo han encontrado su soporte para la defensa de la dignidad en el entorno europeo en el Instrumento de Ratificación del Convenio para la protección de los derechos humanos y la dignidad del ser humano con respecto a las aplicaciones de la Biología y la Medicina (Convenio relativo a los derechos humanos y la biomedicina), hecho en Oviedo el 4 de abril de $1997^{15}$, que en su artículo primero instiga a que las partes en el presente Convenio protejan al ser humano en su dignidad y su identidad y garanticen a toda persona, sin discriminación alguna, el respeto a su integridad y a sus demás derechos y libertades fundamentales con respecto a las aplicaciones de la biología y la medicina ${ }^{16}$.

ticia, Madrid, 1994, p. 359 y ss; de la misma autora «El tratamiento del suicidio en el ordenamiento jurídico penal español", en La ley penal: revista de derecho penal, procesal y penitenciario, n. ${ }^{\circ} 60$, p. 3 y ss.; por último, también de Juanatey, "La disponibilidad del derecho a la vida en la jurisprudencia y en la legislación de los Estados Unidos de América», en Revista Jueces para la democracia, n. ${ }^{\circ} 45$, 2002, pp. 53-66.

${ }^{15}$ Sobre el Convenio de Oviedo se puede consultar De Lorenzo y Motero, Ricardo, Derechos y obligaciones de los pacientes (Análisis de la Ley 41/2002, de 14 de noviembre, básica reguladora de la autonomía de los pacientes y de los derechos de información y documentación clínica), Colex, Madrid, 2003, p. 157 y ss.

16 Sobre este tema muchos estudios han dado su perspectiva. Destacamos en este punto a Fernández de Casadevante Romani, Carlos, «El convenio para la protección de los Derechos Humanos y la dignidad del ser humano con respecto a la aplicación dela Biología y la Medicina: Convención sobre Derechos Humanos y Biomedicina", en Revista de Derecho y Genoma Humano, n. ${ }^{\circ}$, julio-diciembre 1997; también véase sobre la capacidad que se otorga al individuo para tomar las decisiones que afectan a su proyecto vital, Romeo Casabona, Carlos M. ${ }^{a}$, El Derecho y la bioética ante los límites de la vida humana, Centro de Estudios Ramón Areces, Madrid, 1995, p. 42 y ss. 


\section{LA ENTRADA EN ACCIÓN DE LA ÉTICA MÉDICA}

Enlazado con la dignidad no podemos dejar de lado a la ética. Bajo esta premisa se discute sobre un análisis de la ética generalista que defiende una visión universal de los principios y reglas para todos ${ }^{17}$. Difícil resulta encontrar una moral universal, al contrario, los valores morales cambian en función del lugar y el momento en que se estudian. La ética encuadrada aquí en su referencia a lo social o cívico en el marco que analizamos permite que podamos hablar de una ética médica, tal y como configura el Código Deontológico de la Medicina, que condiciona las actuaciones del profesional de salud en base a unos criterios que han sido asumidos como propios por ese gremio y que van a condicionar su práctica diaria ${ }^{18}$. En este sentido el referido Código Deontológico, en su versión actualizada de fecha 15 de octubre de 2018, recoge entre sus preceptos los principios básicos inspiradores de guían las actuaciones de los médicos. En concreto en su artículo 6 acentúa que la profesión médica está al servicio del ser humano y de la sociedad, por lo que respetar la vida humana, la dignidad de la persona y el cuidado de la salud del individuo y de la comunidad son los deberes primordiales del médico.

Cuando se hace referencia a la ética en ningún caso se puede dejar de tener presente los derechos humanos ${ }^{19}$, puesto que los mismos sirven como inspiración, pero al mismo tiempo como parámetro de referencia. En especial, la dignidad se postula como el estandarte que habilita el desarrollo del resto de los derechos en el marco de garantizar el desenvolvimiento de la vida bajo el prisma del máximo respeto a la dignidad humana. De ahí que «el ordenamiento jurídico acata y debe respetar la decisión de la persona en orden a acabar con su propia existencia. Se trata no de otra cosa que del derecho a morir con dignidad. Por ello, en mi opinión, si un tercero colabora a petición de la víctima, convencido, sin duda, de que su decisión es libre, seria y firme, sin ningún tipo de intereses espurios el Derecho penal no debe actuar, como en tantas otras ocasiones tampoco debe hacerlo... ${ }^{20}$. Como se puede observar en esta afirmación de Ruiz Vallido la libertad de decisión del individuo abarca hasta los extremos que le permitan decidir sobre el final de su vida en unas condiciones dignas, permitiéndole en estos casos adoptar libremente el camino a seguir para los últimos momentos del final de la vida ${ }^{21}$. A su vez, la moral no tiene

17 Para analizar esta posición generalista puede consultarse la obra de KüNG, Hans, Proyecto de una ética mundial, trad. Canal Marcos, Trotta, Madrid, 1991; también López Azpitarte, Eduardo, Ética y vida: desafíos actuales, Paulinas, Madrid, 1990.

${ }_{18}$ Puede consultarse para profundizar más sobre esta línea de actuación Simón LoRDA, Pablo y Couceiro Vidal, Azucena, «Decisiones éticas conflictivas en torno al final de la vida. Una introducción general y un marco de análisis», en Oncología 18 (1), 1995.

19 De suma importancia es destacar la obra de Marcos del Cano, Ana M. a, Bioética y derechos humanos, Universidad Nacional de Educación a Distancia, UNED, Servicio de Publicaciones, Madrid, 2011.

${ }^{20}$ Ruiz Vadillo, Enrique, «Comentario al art. 143 del nuevo Código Penal», cit., p. 1821.

${ }^{21}$ En este sentido, véase Beristain, Antonio, Eutanasia: Dignidad y muerte, Depalma, 2. ${ }^{a}$ edición, Buenos Aires, 1991; también en la obra de Casabona se expone el potencial que reconoce 
esa fuerza vinculante de la que goza el derecho. De hecho, «la moral es un imperativo de conducta individualmente asumido o aceptado, aunque no exista un coercimiento externo en su observancia: se acepta o se cumple voluntariamente porque el individuo lo considera en su convicción valioso o bueno. En cambio, la ética consiste en los criterios y teorías sobre el comportamiento correcto, explicado desde la concepción axiológica de que se parta pues aquélla tampoco es unidimensional ${ }^{22}$.

En esencia la dignidad se ha convertido en un valor que está presente e inspira la praxis sanitaria, puesto que "todos tenemos derecho a vivir y la obligación de dejar vivir a los demás, pero también el derecho a morir con dignidad ${ }^{23}$. Tanto es así que el libro blanco sobre normas de calidad y estándares de cuidados paliativos de la Sociedad Europea de Cuidados Paliativos establece que «los cuidados paliativos deben administrarse de forma respetuosa, abierta y delicada, sensible a los valores personales, culturales y religiosos, a las creencias y prácticas del paciente, así como a la legislación de cada país. Como en el caso de la calidad de vida, la dignidad parece ser un concepto individual que abarca diferentes dominios y prioridades dependiendo del paciente. Según se defina, dignidad puede entenderse como una propiedad esencial más que como algo que pueda dañarse o perderse. Desde esta perspectiva, el reto de los cuidados paliativos es proporcionar un entorno donde el paciente pueda sentir y realizar su propia dignidad $»^{24}$. En este sentido la Ley canaria 1/2015, de 9 de febrero introduce una novedad en su artículo 12.2 que consiste en que los pacientes en situación terminal o de agonía, si así lo desean, tienen derecho a que se les proporcionen en el domicilio que designen en el territorio de la Comunidad Autónoma de Canarias los cuidados paliativos que precisen, siempre que se den las condiciones necesarias para ello ${ }^{25}$. Equivalente espíritu es el que sigue el vigente Código Deontológico de la Medicina, puesto que en su artículo 38 se avala la línea legislativa y dogmática que se lleva imponiendo ya desde hace tiempo en nuestro país, al consagrar en su primer apartado que el médico tiene el deber de intentar la curación o la mejoría del paciente, siempre que sea posible; y dice que cuando ésta ya no lo es, tiene la obligación de aplicarle las medidas adecuadas para conseguir su confort, aun cuando de ello pueda derivarse un acortamiento de la vida. Con ello lo que se pretende es evitar lo que comúnmente se conoce como encarnizamiento

al ordenamiento jurídico como verdadero límite que a su vez la bioética postula hacia el final de la vida, en Romeo Casabona, Carlos M. ${ }^{a}$, El Derecho y la Bioética ante los límites de la vida humana, Cera, Madrid, 1994.

22 Romeo Casabona, Carlos M. ${ }^{a}$, «La relación entre la Bioética y el Derecho», en Romeo Casabona (coord.), Derecho biomédico y bioética, Granada, 1998, p. 151.

${ }^{23}$ Ruiz Vadillo, Enrique, "Comentario al art. 143 del nuevo Código Penal», cit., p. 1822.

${ }^{24}$ El libro blanco sobre normas de calidad y estándares de cuidados paliativos de la Sociedad Europea de Cuidados Paliativos, en Monografias de la Sociedad Española de Cuidados Paliativos (SECPAL), n. ${ }^{\circ} 0$ Presentación, mayo 2012.

25 Esto va directamente enlazado con el derecho a la intimidad, que es analizado muy acertadamente por Pérez Luño, Antonio Enrique, «Bioética e intimidad. La tutela de los datos personales biomédicos», en Marcos Cano, Ana M. ${ }^{\text {, }}$, Bioética, Filosofía y Derecho, Centro Asociado de la UNED, Melilla, 2004, pp. 31-59. 
terapéutico al dejar constancia en el segundo apartado de ese mismo artículo que el médico no debe emprender o continuar acciones diagnósticas o terapéuticas perjudiciales para el enfermo, sin esperanza de beneficios, inútiles u obstinadas. Asimismo continúa señalando que debe retirar, ajustar o no instaurar un tratamiento cuando el pronóstico limitado así lo aconseja, debiendo adecuar las pruebas diagnósticas y las medidas terapéuticas y de sostén a la situación clínica del paciente $y$, en definitiva, se le impone la obligación de evitar la futilidad, tanto cuantitativa como cualitativa, en el proceso patológico del paciente.

\section{LA VIDA COMO DISCUTIDA RAZÓN DE LA RESTRICCIÓN DE LA LIBERTAD}

Otro de los preceptos de la Constitución española, tal y como indiqué en líneas anteriores, que puede plantear un beligerante encuadre con el artículo 15 ya citado es el artículo 16, por el que se garantiza la libertad ideológica, religiosa y de culto de los individuos y las comunidades sin más limitación, en sus manifestaciones, que la necesaria para el mantenimiento del orden público protegido por la ley. Asimismo, continúa el precepto apuntando que nadie podrá ser obligado a declarar sobre su ideología, religión o creencias, enfatizando que ninguna confesión tendrá carácter estatal.

Este precepto a su vez, añade que los poderes públicos tendrán en cuenta las creencias religiosas de la sociedad española y mantendrán las consiguientes relaciones de cooperación con la Iglesia católica y las demás confesiones. Al respecto véase cómo las confesiones religiosas al instaurar los criterios por los que se rigen pueden llegar a condicionar ciertas decisiones que afectan a la vida de las personas, o mejor dicho para estos casos, a las decisiones sobre el final de la vida ${ }^{26}$ (al respecto un tema que ha sido ampliamente debatido son los supuestos en los que una confesión religiosa impide la práctica de transfusiones de sangre, que analizados desde un punto de vista valorativo en confrontación con la defensa del derecho a la vida del artículo 15 puede implicar una buena dosis de incertidumbre). Sobre esta base estoy proclive la tesis que defiende que «el derecho a la vida no pierde su condición de derecho subjetivo por el hecho de que la vida represente un valor instrumental de enorme importancia. Al derecho subjetivo a la vida se le podrá contraponer el valor instrumental o el valor intrínseco de la vida, pero lo que no tiene sentido es

26 Sobre esta base, «la moral se vincula con los paradigmas de las diversas confesiones religiosas; por eso cabe hablar de una moral católica distinta de una moral protestante o judía, etcétera. En cambio, la "ética" se refiere a lo social o cívico o científico. Lógicamente, se puede y se suele distinguir la ética médica de la ética empresarial, de la ética cívica, etcétera», BeristaIn, Antonio, «La eutanasia como excepción. Desde la bioética, la biomedicina y el bioderecho», en Claves de la Razón Práctica, n. ${ }^{\circ} 102$, mayo 2000, p. 27. En este sentido no se entiende al bioderecho como una especialidad de la bioética en Marcos del Cano, Ana María, "La biojurídica en España», en Rivista interna zionale di Filosofia del Diritto, vol. Iv, marzo 1994, p. 129. 
desnaturalizar su función de derecho subjetivo porque tenga la vida otras dimensiones igualmente valiosas $»^{27}$.

Igual panorama nos encontramos al poner sobre el tapete la conexión de este artículo $15 \mathrm{CE}$ con los artículos 17 y 20 . Reconoce el segundo el derecho a la libertad y seguridad que tiene toda persona, e impide que nadie pueda ser privado de su libertad, sino con la observancia de lo establecido en este artículo y en los casos y en la forma prevista en la ley. También el artículo 20 perfila los derechos que gozan de protección, que en este campo destacamos el expuesto en el apartado a), que reconoce la capacidad para expresar y difundir libremente los pensamientos, ideas y opiniones mediante la palabra, el escrito o cualquier otro medio de reproducción. Así como también el expuesto en el apartado d), que permite comunicar o recibir libremente información veraz por cualquier medio de difusión, garantizando mediante la ley el derecho a la cláusula de conciencia y al secreto profesional en el ejercicio de estas libertades. Termina este precepto instituyendo los límites intrínsecos en las propias libertades que están en los derechos reconocidos en la propia Constitución, en los preceptos de las leyes que la desarrollan y, especialmente, en el derecho al honor, a la intimidad, a la propia imagen y a la protección de la juventud y de la infancia.

De la exposición de estos artículos de la Carta Magna en su análisis combinado con el artículo 15 se desprende un potencial desafío. Puesto que si en estos preceptos se prima el derecho a la libertad, garantizando su ejercicio pleno y efectivo, vemos cómo esa pretendida libertad goza de restricciones ${ }^{28}$ a la hora de que un sujeto decida o no libremente poner fin a su vida mediante prácticas eutanásicas.

Recibido: 10-2-2020; ACEPTADO: 24-3-2020

${ }^{27}$ Miraut Martín, Laura, «El testamento vital como expresión de la autonomía individual», cit., p. 167.

${ }^{28}$ La limitación en la materialización de los diferentes derechos en una realidad «porque el absolutismo no sólo viene objetado por cláusulas externas limitadoras o suspensivas, si no por la constante necesidad de compatibilizar la aplicación práctica de los distintos derechos humanos», PÉrez Luño, Antonio E., "Concepto y concepción de los derechos humanos (Acotaciones a la Ponencia de Francisco Laporta)", en Doxa, n. ${ }^{\circ} 4,1987$, p. 55. 


\section{REFERENCIAS BIBLIOGRÁFICAS}

Álvarez del Rio, Asunción, Práctica y ética de la eutanasia, Fondo de Cultura Económica, México, 2005.

Ara Pinilla, Ignacio, «Los frentes abiertos del testamento vital», en López Hernández, José, Navarro Aznar, Fernando y Ramón Torres, José (eds.), Estudios de Filosofía del Derecho y Filosofia Politica. Homenaje al Profesor Alberto Montoro Ballesteros, Universidad de Murcia, 2013.

Ara Pinilla, Ignacio, «La autocomplacencia estética de la cultura jurídica», en Sánchez Bravo, Álvaro (dir.), Democracia, pluralismo y derechos humanos, Cívitas, Pamplona, 2019.

Beristain, Antonio, Eutanasia: Dignidad y muerte, Depalma, 2. a edición, Buenos Aires, 1991.

Beristain, Antonio, «La eutanasia como excepción. Desde la bioética, la biomedicina y el bioderecho", en Claves de la Razón Práctica, n. ${ }^{\circ}$ 102, mayo 2000.

Blázquez Ruiz, Javier, Derechos Humanos y Proyecto Genoma, Biblioteca de Derecho y ciencia de la vida, Comares, Granada, 1999.

Cortina, Adela, Ética aplicada y democracia radical, Tecnos, Madrid, 1993.

De Lorenzo y Motero, Ricardo, Derechos y obligaciones de los pacientes (Análisis de la Ley 41/2002, de 14 de noviembre, básica reguladora de la autonomía de los pacientes y de los derechos de información y documentación clínica), Colex, Madrid, 2003.

Diez Ripollés, José Luís, «Eutanasia y Derecho», en Anuario Filosofía del Derecho, tomo XII, 1995.

Díez Ripollés, José Luís y Muñoz Sánchez, Juan, El tratamiento jurídico de la Eutanasia. Una perspectiva de Derecho comparado, Tirant lo Blanc, Valencia 1996.

Dworkin, Ronald, El dominio de la vida, Ariel, Madrid, 1994.

Fernández de Casadevante Romani, Carlos, «El convenio para la protección de los Derechos Humanos y la dignidad del ser humano con respecto a la aplicación de la Biología y la Medicina: Convención sobre Derechos Humanos y Biomedicina», en Revista de Derecho y Génoma Humano, n. ${ }^{\circ}$ 7, julio-diciembre 1997.

Gracia, Diego (ed.), Morir con dignidad: Dilemas éticos en el final de la vida, Fundación de Ciencias de la Salud - Editorial Doce Calles, Madrid, 1996.

Hotal, Augusto, Ética I, Universidad de Comillas, Madrid, 1994.

Juanatey Dorado, Carmen, Derecho, suicidio, eutanasia, Servicio de Publicaciones de la Secretaría del Ministerio de Justicia, Madrid, 1994.

Juanatey Dorado, Carmen, «El tratamiento del suicidio en el ordenamiento jurídico penal español», en La ley penal: revista de derecho penal, procesal y penitenciario, n. ${ }^{\circ}$ 60, 2009.

Juanatey Dorado, Carmen, «La disponibilidad del derecho a la vida en la jurisprudencia y en la legislación de los Estados Unidos de América», en Revista Jueces para la democracia, n. ${ }^{\circ}$ 45, 2002.

Küng, Hans, Proyecto de una ética mundial, trad. Canal Marcos, Trotta, Madrid, 1991.

López Azpitarte, Eduardo, Ética y vida: desafíos actuales, Paulinas, Madrid, 1990.

Marcos del Cano, Ana María, «La biojurídica en España», en Rivista interna zionale di Filosofia del Diritto, vol. IV, marzo 1994.

Marcos del Cano, Ana María, Bioética y derechos humanos, Universidad Nacional de Educación a Distancia, UNED, Servicio de Publicaciones, Madrid, 2011. 
Miraut Martín, Laura, «El testamento vital como expresión de la autonomía individual», en Miraut Martín, Laura (editora), Imágenes contemporáneas de la realización de los derechos en la cultura jurídica iberoamericana, Dykinson, Madrid, 2018.

Nuñez Paz, Miguel Ángel, Homicidio consentido, eutanasia y derecho a morir con dignidad, Tecnos, Madrid, 1999.

Pérez GonzÁlez, David E., «Revisión de los valores implicados en el proceso de emancipación individual en la sociedad trasnacional», en Revista de Derecho UNED, n. ${ }^{\circ}$ 14, UNED, 2014.

Pérez Luño, Antonio E, «Concepto y concepción de los derechos humanos (Acotaciones a la Ponencia de Francisco Laporta)", en Doxa, n. ${ }^{\circ}$ 4, 1987.

Pérez Luño, Antonio Enrique, «Bioética e intimidad. La tutela de los datos personales biomédicos», en Marcos Cano, Ana M. ${ }^{a}$, Bioética, Filosofía y Derecho, Centro Asociado de la UNED, Melilla, 2004.

Rodríguez Calero, Juan M., Creación judicialy derechos fundamentales, Universidad Libre, Bogotá, 2012.

Romeo Casabona, Carlos M. ${ }^{a}$, El Derecho y la Bioética ante los límites de la vida humana, Cera, Madrid, 1994.

Romeo Casabona, Carlos M. ${ }^{a}$, El Derecho y la bioética ante los límites de la vida humana, Centro de Estudios Ramón Areces, Madrid, 1995.

Romeo Casabona, Carlos M. a " «La relación entre la Bioética y el Derecho» en Romeo Casabona (coord.), en Derecho biomédico y bioética, Granada, 1998.

Ruiz Vadillo, Enrique, «El derecho a la vida y a la integridad física», en XII Jornadas de Estudio. Los Derechos Fundamentales y Libertades Públicas, vol. 1, Secretaria General Técnica, Centro de Publicaciones, Madrid, 1992.

Ruiz Vadillo, Enrique, «Comentario al art. 143 del nuevo Código penal», en Conde-Pumpido Ferreiro, Cándido (dir.), Código Penal. Doctrina y Jurisprudencia, tomo II, Trivium, Madrid, 1997.

SAnz-Ortíz, Jaime, «¿Es posible gestionar el proceso de morir? Voluntades anticipadas», en Medicina Clinica, vol. 126, abril 2006.

Simón Lorda, Pablo y Couceiro Vidal, Azucena, «Decisiones éticas conflictivas en torno al final de la vida. Una introducción general y un marco de análisis», en Oncología 18 (1), 1995.

Sociedad Española de Cuidados Paliativos (SECPAL), El libro blanco sobre normas de calidad y estándares de cuidados paliativos de la Sociedad Europea de Cuidados Paliativos, en Monografias de la Sociedad Española de Cuidados Paliativos (SECPAL), n. ${ }^{\circ} 0$ Presentación, mayo 2012.

Suarez Llanos, Leonor, «La ley de la muerte. Eutanasia, ética y derechos», en Anuario de Filosofía del Derecho, tomo xxviII, 2012. 
